\title{
Efeito da absorção de água e do tipo de substrato no desempenho de argamassa de revestimento nos estados fresco e endurecido
}

\author{
The effect of water absorption and type of substrate on \\ the performance of rendering mortars in the fresh and \\ hardened state
}

\begin{abstract}
Heitor Montefusco Bernardo
Roberto Cesar de Oliveira Romano

Maria Alba Cincotto

Rafael Giuliano Pileggi

\section{Resumo}

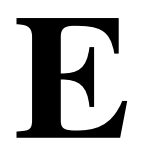

ste trabalho foi realizado com o objetivo de avaliar o impacto do tipo de substrato e do tratamento da superfície na resistência de aderência e na permeabilidade de argamassa de revestimento. Para tanto, uma mesma argamassa foi aplicada sobre blocos cerâmico e de concreto, e substrato-padrãode concreto, nos quais foram realizados tratamentos superficiais com hidrofugantee silicone para alterar os níveis de absorção de água sem mudar a rugosidade superficial. Todas as condições de mistura, aplicação e cura foram mantidas constantes e os resultados indicaram que há considerável diferença no espalhamento e no tempo em aberto das argamassas em função do tipo de substrato ou tratamento superficial; não houve diferença estatística nos resultados de resistência de aderência ou permeabilidade das argamassas aplicadas sobre os blocos cerâmico e de concreto, independente do tratamento da superfície, porém os valores foram menores do que para as argamassas aplicadas sobre o substratopadrão de concreto; e apesar de o coeficiente de absorção de água dos substratos influenciar diretamente os parâmetros avaliados, para cada tipo de substrato foi observada uma tendência, indicando que a absorção é importante, porém não é a variável de maior interferência na aderência argamassa-substrato.

Palavras-chave: Argamassa. Substrato. Tratamento de superfície. Aderência e permeabilidade.

${ }^{1}$ Heitor Montefusco Bernardo 'Universidade de São Paulo São Paulo - SP - Brasil

${ }^{2}$ Roberto Cesar de Oliveira Romano

2Universidade de São Paulo São Paulo - SP - Brasil

${ }^{3}$ Maria Alba Cincotto 3Universidade de São Paulo São Paulo - SP - Brasil

${ }^{4}$ Rafael Giuliano Pileggi ${ }^{4}$ Universidade de São Paulo São Paulo - SP - Brasil

Recebido em 05/06/19 Aceito em 27/07/19

\section{Abstract}

The main purpose of thisstudywas to evaluate the impact of the substrate type and water absorption on the properties of rendering mortars. Amortarwasapplied on ceramic and concreteblocks and on standardconcretesubstrate, whichreceivedsuperficialtreatments with water repellent and silicon. This strategy was used to alter the water absorption without changing the roughness. The mixture, application, and cure of the mortars were kept constant, and the results indicated that there are considerable differences in the spreading and open-time of mortars depending on the surface treatment and substrate type; there were no statistical differences in the adhesion or permeability of mortars applied on the ceramic and concrete blocks, regardless of surface treatment, but the values were much lower thanthose observed on the standard concrete substrate; and even with a direct influence of the coefficient of water absorption on adhesion and permeability, a differenttendencywasobservedfor each kind of substrate, indicating that, whileabsorption is important, it is not the main variable influencing the performance of coatings.

Keywords: Mortar. Substrat. Surface treatment. Adhesion and permeability.
\end{abstract}

BERNARDO, H. M.; ROMANO, R. C. de O.; CINCOTTO, M. A.; PILEGGI, R. G. Efeito da absorção de água e do tipo de substrato no desempenho de argamassa de revestimento nos estados fresco e endurecido. Ambiente Construído, Porto Alegre, v. 20, n. 3, p. 493-511, jul./set. 2020. 


\section{Introdução}

Os revestimentos de argamassa têm como funções principais a proteção dos elementos de vedação da ação direta dos agentes agressivos, melhora do conforto térmico e acústico, regularização da superfície, podendo ser utilizados como revestimento final ou servir de base para outra camada de revestimento, contribuir para a estética de vedações e fachadas, entre outros (ROMANO, 2013).

Seu desempenho e durabilidade são definidos a partir de diversos tipos de ensaio, que podem ser realizados somente na argamassa ou após a aplicação do revestimento sobre diferentes substratos.

A resistência de aderência é uma propriedade de grande relevância para os revestimentos e, apesar de ter sido alvo de inúmeras pesquisas, os parâmetros que determinam o contato de matrizes cimentícias a substratos ainda não são bem compreendidos, dificultando o estabelecimento de métodos para o aperfeiçoamento dessa região (NAKAKURA; CINCOTTO, 2004).

Trata-se da resistência às tensões atuantes na interface com o substrato (ABNT, 2010a) e, por esse motivo, não é considerada como propriedade da argamassa, mas como fruto da interação entre as camadas dos constituintes do sistema de revestimento (COSTA, 2014; MACIEL et al., 1998).

Os estudos reportados em literatura dão ênfase nas alterações da microestrutura da interface, como composição, morfologia e densidade dos produtos hidratados (ANTUNES, 2006), ou às características superficiais do substrato, como rugosidade, porosidade/absorção de água, etc. (COSTA, 2014).

Por exemplo, em testes realizados em laboratório, Paes et al. (2014) identificaram que as argamassas aplicadas sobre blocos de concreto atingiram uma média de resistência de aderência pouco mais de $50 \%$ maior que para as argamassas aplicadas sobre blocos cerâmicos. Nesse caso, cada material foi aplicado sobre um único bloco, sem a presença de juntas, mas os resultados convergiram com a avaliação em campo realizada por Nakakura, Munhoz e Battagin (2008), pois os blocos são considerados o elo frágil do conjunto, visto que a resistência de aderência das argamassas aplicadas nas juntas é cerca de $70 \%$ maior do que nos blocos (ANGELIM; ANGELIM; CARASEK, 1996).

No trabalho realizado por Tempet al. (2013), constatou-se que para um mesmo material, no caso o bloco cerâmico, a rugosidade superficial contribuiu de forma significativa para a melhora da aderência. Sendo assim, não há dúvida que o substrato exerce considerável influência na resistência de aderência das argamassas, pois apresentam diferentes rugosidades e velocidades de absorção da fase líquida.

Por isso, é prática comum a utilização de tratamentos superficiais para alterar as pontes de aderência nos substratos com menor potencial de ancoramento do revestimento, como aplicação de chapisco, texturização (sulcos), umedecimento (com ou sem cal), aplicação de aditivos orgânicos, entre outros (CARASEK; SCARTEZINI, 1999), pois o revestimento aplicado deve permanecer aderido por toda vida útil do sistema.

Da mesma forma, a permeabilidade das argamassas é outra propriedade de grande interesse para a avaliação da durabilidade do sistema de revestimento, pois uma das demandas é tornar o conjunto estanque à penetração dos agentes de degradação (ROMANO; TORRES; PILEGGI, 2015). Trata-se de uma forma de avaliação da facilidade com que um fluido, submetido a um gradiente de pressão, percola os vazios em um meio poroso.

Como a permeabilidade é uma medida que depende da estrutura do material, além de ter relação direta com a porosidade, é influenciada pela distribuição, morfologia e conectividade dos poros (INNOCENTINI et al., 2009). Por isso, esse tipo de medida pode prover um indicativo das condições da estrutura porosa das argamassas no momento do ensaio, servindo ainda como método de controle de qualidade e avaliação dos processos de produção (SENTONE, 2011). Alémdisso, o desenvolvimento da microestrutura apresenta relação com a absorção de água do substrato: quanto mais rápida a perda de umidade, maior a pressão interna na argamassa para a saída do líquido afetando a criação dos poros.

Como se tratam de propriedades que têm relação direta com a durabilidade dos componentes cimentícios, a avaliação da argamassa aplicada sobre distintos substratos pode fornecer informações bastante representativas do material em uso.

Neste trabalho serão apresentados resultados da resistência de aderência à tração e da permeabilidade ao ar de argamassa de revestimento aplicadas sobre blocos de concreto e cerâmico, e substrato-padrãode concreto (NBR 14082:2004 - Anexo B), sobre os quais foram aplicados hidrofugante (à base de emulsão de octiltrietoxisilano) ou silicone líquido (viscosidade de $10 \mathrm{cSt}$ ). Essa estratégia permitiu avaliar o impacto do tipo de substrato, da rugosidade superficial e da absorção da fase líquida pelo substrato.

494 Bernardo, H. M.; Romano, R. C. de O.; Cincotto, M. A.; Pileggi, R. G. 


\section{Método aplicado}

O método aplicado para a execução do trabalho consistiu em (ROMANO; TORRES; PILEGGI, 2015):

(a) lavagem dos substratos, secagem por $24 \mathrm{~h}$ em estufa a $80{ }^{\circ} \mathrm{C}$ e aplicação dos tratamentos. Esse estágio foi realizado para a eliminação de material pulverulento da superfície e dos poros;

(b) aplicação do tratamento com silicone ou hidrofugante;

(c) caracterização dos substratos a partir dos métodos de ensaio detalhados a seguir;

(d) moldagem da argamassa nos diferentes substratos e com distintos tratamentos; e

(e) caracterização dos revestimentos aplicados.

Foram avaliados 9 sistemas, combinando 3 substratos, e os tratamentos de superfície:

(a) bloco cerâmico;

(b) bloco cerâmico com tratamento com silicone;

(c) bloco cerâmico com tratamento com hidrofugante;

(d) bloco de concreto;

(e) bloco de concreto com tratamento com silicone;

(f) bloco de concreto com tratamento com hidrofugante;

(g) substrato-padrão de concreto;

(h) substrato-padrão de concreto com tratamento com silicone; e

(i) substrato-padrão de concreto com tratamento com hidrofugante.

O substrato-padrão de concreto foi adquirido junto à Associação Brasileira de Cimento Portland, produzido de acordo com a NBR 14082 - Anexo B (ABNT, 2004).

O tratamento dos substratos foi realizado com silicone líquido com viscosidade de 10 cSt (Dow Corning), com densidade de $0,95 \mathrm{~g} / \mathrm{cm}^{3}$ e tensão superficial $0,021 \mathrm{~N} / \mathrm{m}$, ou hidrofugante à base de emulsão de octiltrietoxisilano, fórmula molecular $\mathrm{CH}_{3}\left(\mathrm{CH}_{2}\right)_{7} \mathrm{Si}\left(\mathrm{OCH}_{2} \mathrm{CH}_{3}\right)_{3}$ (Dow Corning), com pH 4,9 e densidade $1,02 \mathrm{~g} / \mathrm{cm}^{3}$. Neste último caso, o produto foi diluído em uma proporção hidrofugante:água deionizada 1:9, conforme caracterizado no trabalho de Costa (2014).

Ambos os produtos foram aplicados em 3 demãos, com tempo de espera de $1 \mathrm{~h}$ entre camada. Após a última aplicação o bloco foi seco por $24 \mathrm{~h}$ para a aplicação da argamassa.

\section{Métodos de ensaio}

\section{Caracterização das matérias-primas}

(a) distribuição granulométrica dos finos: determinada no granulômetro a laser Helos (Sympatec) com faixa de detecção $0,1 \mu \mathrm{m}$ a $350 \mu \mathrm{m}$;

(b) distribuição granulométrica das areias: realizada por análise dinâmica de imagens (ADI) no equipamento QICPIC - Sympatec. Foram analisados aproximadamente $100 \mathrm{~g}$ de cada material, com lente M7 (faixa de análise entre $10 \mu \mathrm{m}$ e $3.410 \mu \mathrm{m}$ ) e dispersão por gravidade;

(c) área superficial específica: determinada a partir do método de adsorção multicamadas de gás, BET (Brunauer, Emmett, Teller), em um equipamento Belsorp Max, com pré-tratamento das amostras em temperatura de $60^{\circ} \mathrm{C}$ e pressão de $10^{-2} \mathrm{kPa}$ por $24 \mathrm{~h}$ no equipamento Belprepvac-II para retirada da umidade e de outros gases adsorvidos. No caso do cimento o pré-tratamento foi realizado sob temperatura menor (40 ${ }^{\circ} \mathrm{C}$ ) e em menor tempo $(16$ h) para evitar o risco de desidratação da gipsita (MANTELLATO; PALACIOS; FLATT, 2015); e

(d) densidade real: realizada no equipamento Multipycnometer, da marca Quantachrome MVP 5DC, e o resultado quantificado por uma média de 5 determinações para cada matéria-prima. Antes de iniciar o ensaio, a matéria-prima foi seca em estufa por $24 \mathrm{~h}$ a $60^{\circ} \mathrm{C}$. 
Após a determinação das características físicas das matérias-primas, os parâmetros de empacotamento e mobilidade teóricos foram quantificados a partir do modelo de Westman e Hugill (OLIVEIRA et al., 2000; ROMANO; TORRES; PILEGGI, 2015).

\section{Caracterização dos substratos}

(a) rugosidade superficial: a topografia da superfície foi medida pela técnica de interferometria a laser, em um perfilômetro óptico modelo NP-Flex, Bruker. As avaliações foram realizadas somente nos substratos sem tratamento, visto que a aplicação de hidrofugante ou silicone não afetou a topografia dos substratos (COSTA, 2014). O princípio da técnica foi detalhado por Costa (2014) e neste trabalho o resultado é expresso como índice de superfície;

(b) absorção de água por capilaridade: determinada conforme detalhado por Carbone et al. (2013). Os ensaios foram realizados em amostras com dimensões de $160 \mathrm{~mm}$ x $40 \mathrm{~mm}$. Para isso, os blocos cerâmico e de concreto e o substrato-padrão de concreto foram cortados utilizando uma serra (Clipper, CM41). As bordas foram impermeabilizadas com cera de abelha. A face de interesse foi colocada em contato com a água e, após períodos pré-determinados, são registradas as massas de água absorvidas. O coeficiente de capilaridade $W$, expresso em $\mathrm{kg} / \mathrm{m}^{2} \cdot \mathrm{h}^{1 / 2}$, é obtido pela Equação 1, segundo as diretrizes da norma EN ISO 15148 (BRITISH..., 2002), onde $A$ é a área $\left(\mathrm{m}^{2}\right), t$ é o tempo em horas e $m_{t}$ e $m_{i}$ são as massas total e inicial, em kg; e

$W=\frac{m_{t}-m_{i}}{A \times \sqrt{t}}$

(c) ângulo de contato da gota por goniometria: determinados em um goniômetro Krüss - DSA 100, Easy Drop, utilizando-se água deionizada a partir da técnica da gota séssil. A gota foi depositada sobre a superfície por meio de uma microseringa, sempre com o volume de $2 \mu \mathrm{L}$ e fotografada com ampliação em uma lente de baixo aumento, conforme ilustrado na Figura 1. Como o ângulo de contado pode variar se houver escoamento da gota pela superfície, mesmo não havendo absorção, as medidas foram realizadas em função do tempo, até 5 min de repouso sobre a substrato (ROMANO, 2013). A Equação 2 ilustra como o ângulo de contato da gota $(\theta)$ com a superfície foi calculado, sendo $r$ o raio e $h$ a altura da gota.

$\mathrm{O}$ valor do ângulo de contato, medido entre a base e a tangente à superfície do líquido no ponto de contato com a base, depende da energia de superfície da amostra e da tensão superficial do líquido. Se a gota se esparramar por toda a superfície, seu ângulo de contato será de aproximadamente zero, mas se o espalhamento for parcial, o ângulo de contato variará de $0^{\circ}$ a $180^{\circ}$. Quanto maior o ângulo, menor a capacidade de molhamento, conforme apresentado na Figura 2.

$\theta=\operatorname{sen}^{-1}\left[\frac{2 r h}{r^{2}+h^{2}}\right]$

Figura 1 - Ilustração da gota séssil e equação para o cálculo do ângulo de contato com a superfície não absorvente

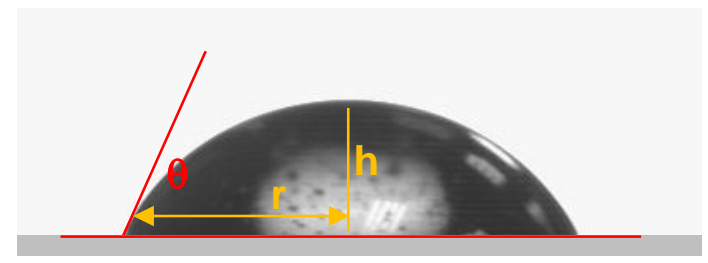

Figura 2 - Variação do ângulo de contato da gota com a superfície

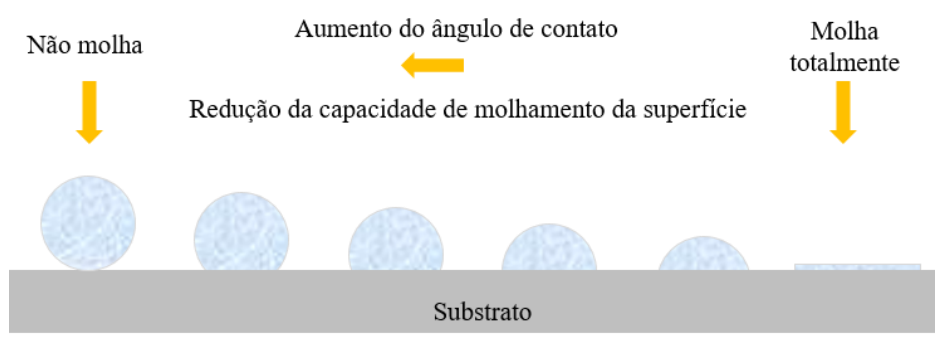

Nota: *dosada em função da massa total de pó.

496 Bernardo, H. M.; Romano, R. C. de O.; Cincotto, M. A.; Pileggi, R. G. 


\section{Composição da argamassa e parâmetros da formulação}

A Figura 3 ilustra a distribuição discreta de tamanho de partículas das matérias primas e da argamassa (linha tracejada) calculada com base no proporcionamento dos pós. Optou-se por formular uma argamassa com distribuição granulométrica contínua e elevada quantidade de material fino para otimizar o preenchimento dos vazios nas distintas rugosidades dos substratos. A composição-padrão adotada é ilustrada na Tabela 1.

As argamassas industrializadas são comumente formuladas com aditivos incorporadores de ar e retentores de água, mas no caso da utilizada neste trabalho não foram utilizados esses aditivos para evitar a geração de grande quantidade de bolhas de ar, fato que poderia interferir no preenchimento da interface blocoargamassa.

Na Tabela 2 são apresentados os valores dos parâmetros da formulação, levando em consideração o teor de $15 \%$ em massa de água utilizada para a mistura.

Uma matriz monodispersa não preenche toda a superfície do substrato, visto que não há compatibilidade geométrica entre partícula-irregularidade do substrato, mas em sistemas polidispersos as partículas mais finas tendem a migrar para a superfície do substrato, aumentando o contato efetivo matriz-substrato (COSTA, 2014). Por isso, optou-se por formular uma argamassa com maior quantidade de finos, mas com adequada fluidez para proporcionar melhor preenchimento das irregularidades dos substratos que, conforme apresentado mais adiante, apresentavam distintas rugosidades.

Tabela 1 - Composição da argamassa utilizada neste trabalho

\begin{tabular}{l|c}
\hline \multicolumn{1}{c|}{ Matéria prima } & \% em volume \\
\hline Cimento Portland - CPIIF & 18,7 \\
Filler calcário & 30,5 \\
Cal - CHI & 5,60 \\
Areia fina & 25,1 \\
Arreia média & 20,1 \\
Água & $15 \% *$ \\
\hline
\end{tabular}

Nota: *dosada em função da massa total de pó.

Figura 3 - Distribuição granulométrica das matérias-primas e da argamassa (linha tracejada)

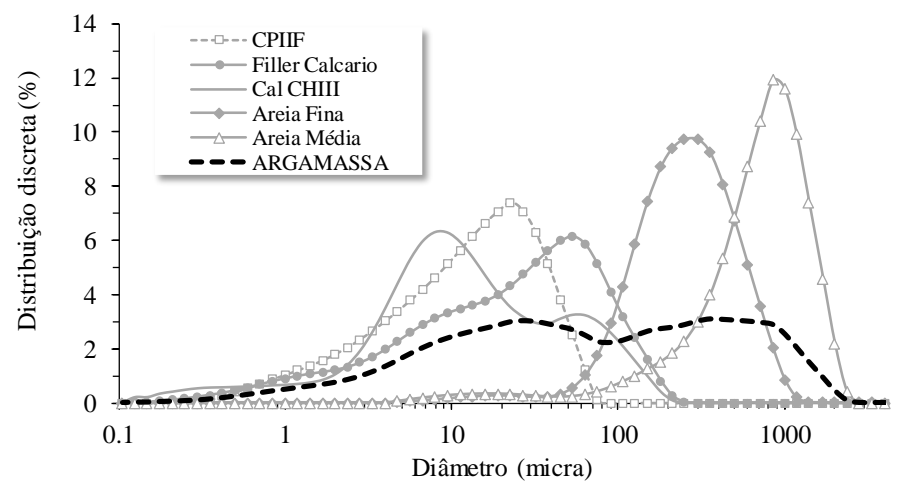

Tabela 2 - Parâmetros da formulação

\begin{tabular}{l|c}
\hline \multicolumn{1}{c|}{ Parâmetro } & Argamassa \\
\hline Porosidade de empacotamento $(\%) *$ & 6,50 \\
Área superficial específica $\left(\mathrm{m}^{2} / \mathrm{g}\right)$ & 1,14 \\
Densidade real do pó $\left(\mathrm{g} / \mathrm{cm}^{3}\right)$ & 2,80 \\
Área superficial volumétrica $\left(\mathrm{m}^{2} / \mathrm{cm}^{3}\right)$ & 3,20 \\
Densidade da argamassa fresca $\left(\mathrm{g} / \mathrm{cm}^{3}\right)$ & 2,27 \\
Distância média de separação entre as partículas finas - IPS $(\mu \mathrm{m}) * *$ & 0,24 \\
Espessura da camada de pastas que afasta os agregados - MPT $(\mu \mathrm{m}) * *$ & 9,82 \\
\hline
\end{tabular}

Nota: *determinada a partir do modelo de Westman e Hugill (ROMANO; TORRES; PILEGGI, 2015); e **definição e cálculo encontrados em (OLIVEIRA et al., 2000). 


\section{Consistência da argamassa aplicada}

Squeezeflow realizado seguindo as recomendações da norma técnica brasileira NBR 15839 (ABNT, 2010b) - Argamassa de assentamento e revestimento de paredes e tetos - Caracterização reológica pelo método squeezeflow. Os ensaios foram realizados em uma prensa Instron 3345 após moldagem das amostras (101 $\mathrm{mm}$ de diâmetro x $20 \mathrm{~mm}$ de altura) sobre os diferentes tipos de substrato, com controle de deslocamento de $0,1 \mathrm{~mm} / \mathrm{s}$. Os ensaios foram realizados até o deslocamento final de $18 \mathrm{~mm}$ ( $90 \%$ da espessura da amostra) ou até atingir a carga máxima de $200 \mathrm{~N}$. Na Figura 4 é apresentado um esquema ilustrativo com o passo a passo de preparo da amostra sobre o bloco cerâmico, procedimento aplicado também para os blocos de concreto e substrato-padrão de concreto. Em (i) é ilustrado o posicionamento do molde, em (ii) a adição da argamassa, em (iii) o completo preenchimento do molde, em (iv) o nivelamento da superfície e, em (v) e (vi) as amostras prontas para o ensaio e durante o teste, respectivamente. Todos os ensaios foram realizados 5 min após a preparação e após 30 min de repouso visando monitorar o impacto da absorção de água pelo substrato.

\section{Moldagem para avaliação do estado endurecido}

A fim de eliminar a etapa de corte com serra-copo para adequação das amostras para ensaio de arrancamento, e diminuir a variabilidade dos resultados, optou-se por efetuar as moldagens das argamassas sobre os diferentes tipos de substrato conforme proposto por Romano (2013).

Inicialmente os blocos foram divididos em oito quadrantes e o tratamento das superfícies realizado de forma aleatória. Da mesma forma, os moldes, com diâmetro de $50 \mathrm{~mm}$ e espessura de $20 \mathrm{~mm}$, foram dispostos aleatoriamente sobre os blocos, conforme ilustrado na Figura 5, independente do tratamento das superfícies e do tipo de substrato. Cada batelada de argamassa foi misturada com $2 \mathrm{~kg}$ de pó, sendo, dessa forma, a moldagem realizada em três etapas, a fim de se preencher todos os moldes. A Figura 5 indica o posicionamento dos moldes para a primeira etapa.

Após a moldagem, os blocos foram colocados dentro de sacos plásticos e lacrados para evitar a perda de umidade. Em cada saco foi colocado um copo com água para manter a umidade relativa próxima a $100 \%$, e os blocos acondicionados em uma câmara com controle de temperatura de $23{ }^{\circ} \mathrm{C} \pm 2$. Após 28 dias de cura, os blocos foram retirados do saco e colocados em câmara seca para evaporação da água livre na argamassa e, uma semana depois, iniciada a realização dos ensaios, conforme detalhado na sequência.

Figura 4 - llustração da etapa de moldagem das amostras sobre o bloco cerâmico, para o ensaio de squeezeflow - o mesmo procedimento foi utilizado também para o bloco de concreto e substratopadrão - (i) posicionamento do molde; (ii) a adição da argamassa; (iii) preenchimento do molde; (iv) nivelamento da superfície; e (v) e (vi) amostras prontas para o ensaio e durante o teste, respectivamente
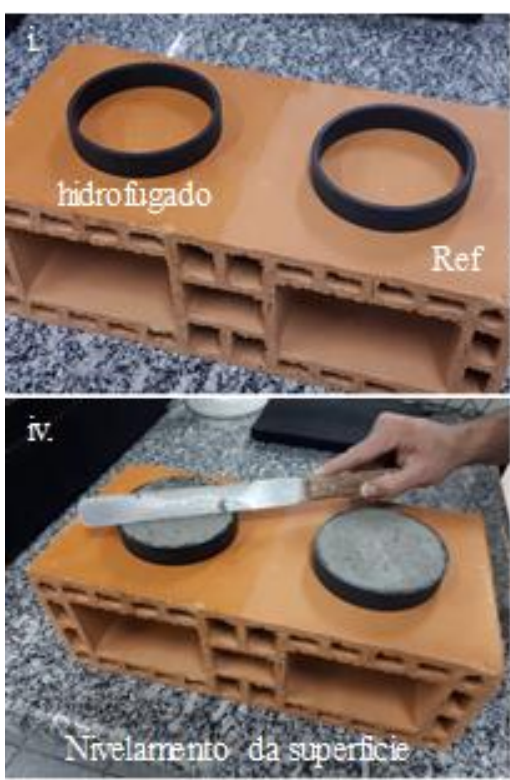
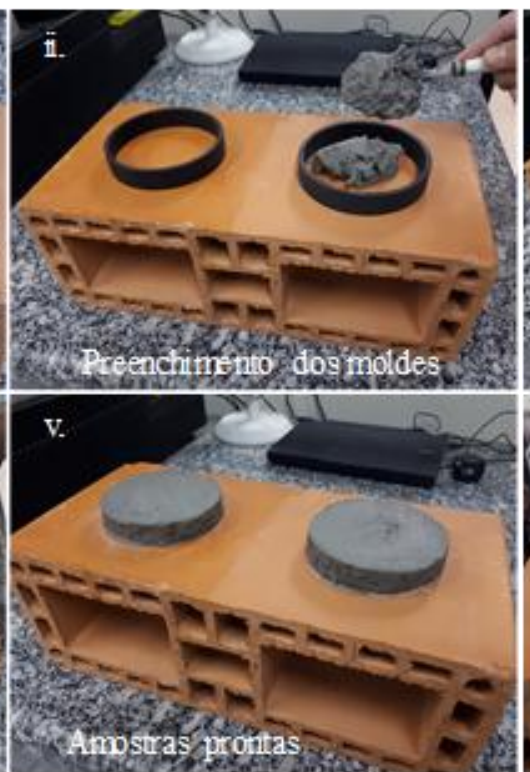

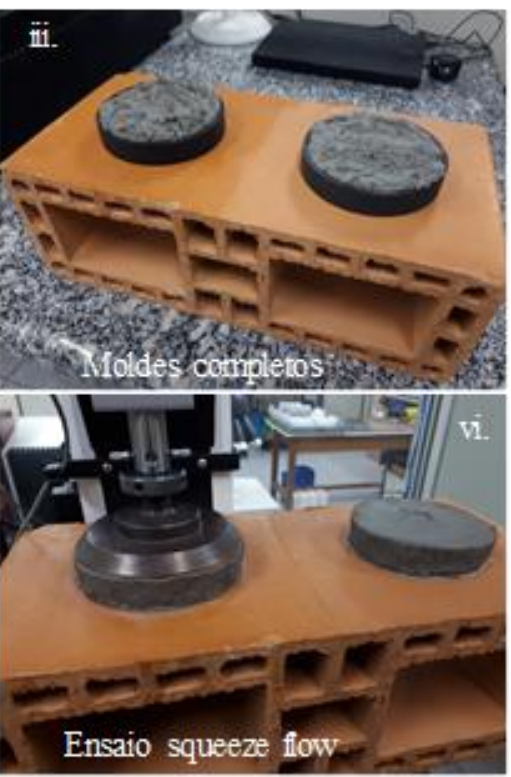

498 Bernardo, H. M.; Romano, R. C. de O.; Cincotto, M. A.; Pileggi, R. G. 
Figura 5 - Ilustração dos blocos utilizados para a moldagem das argamassas - na foto é indicado o posicionamento aleatório dos moldes para eliminar o efeito da variabilidade dos blocos nos resultados

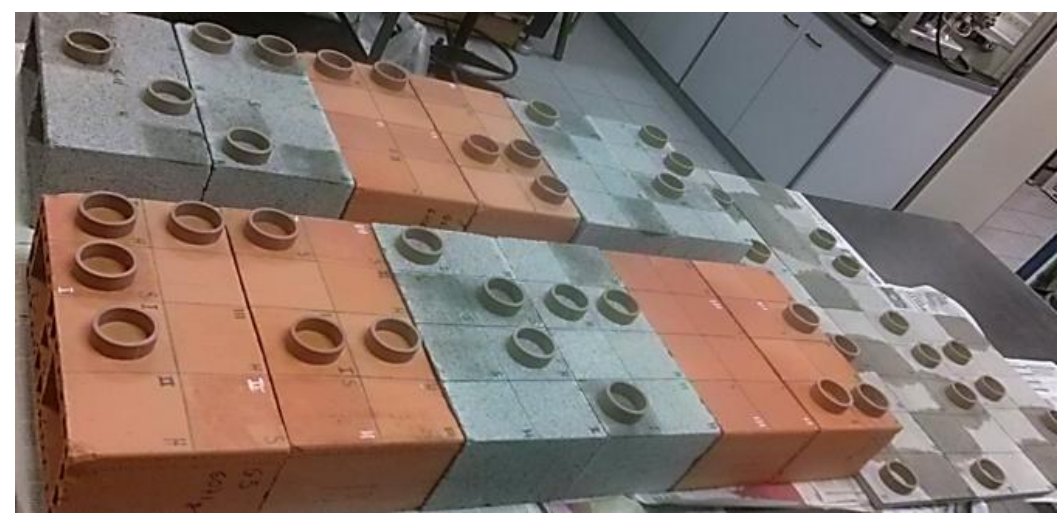

(a) resistência de aderência à tração: os ensaios foram realizados utilizando um dinamômetro digital, Imada, modelo ATX-500 DPU e célula de carga de 5 kN, Dynatest, com precisão de 1,0 N, conforme apresentado no trabalho de Romano (2013). As pastilhas metálicas foram coladas com massa plástica (Maxxi Rubber); e

(b) permeabilidade ao ar: estimada a partir da técnica de vacuum-decay (TORRENT, 1992; TORRENT; FRENZER, 1995). O princípio da técnica é detalhado no trabalho de Sentone (2011). O equipamento consiste basicamente em uma bomba de vácuo ligada a uma câmara de sucção de nylon que fica em contato com uma superfície da argamassa, onde é formada, inicialmente, uma região de pressão negativa. Quando a bomba de vácuo é ligada, um transdutor registra as variações de pressão ao longo do tempo de ensaio e os dados coletados em uma placa de aquisiçãoligada ao computador. Uma válvula solenoide restringe o fluxo de ar somente no sentido da argamassa à bomba de vácuo, para permitir que a recuperação de pressão na câmara aconteça apenas de uma face a outra do corpo de prova. Para a realização dos ensaios a ventosa foi fixada ao corpo de prova com massa de calafetar de modo a evitar a entrada de ar durante o teste. Acionouse, então, a bomba de vácuo, até a estabilização da pressão negativa, na qual foi mantida por cerca de 1 min. Após esse tempo, a bomba de vácuo foi desligada e o tempo de decaimento da pressão quantificado. Oresultado da permeabilidade das argamassas foi obtido a partir da Equação 3, de Darcy (INNOCENTINI et al., 2009).

$\frac{\Delta P}{L}=\frac{\mu}{k_{1}} \cdot v_{S}$

Onde:

$\Delta P$ é a diferença entre a pressão de entrada e saída do ar;

$L$ é a espessura da amostra;

$\mu$ é a viscosidade do fluido;

$v_{s}$ é a velocidade superficial; e

$k_{l}$ é a constante de permeabilidade.

Darcyana, ou viscosa, propriedade apenas da estrutura porosa. Nesse caso, o fluido perde energia de dois modos:

(a) pelo atrito entre as moléculas do fluido durante o escoamento, ou seja, quanto maior a viscosidade do fluido, maior será o atrito e consequentemente a transformação da energia de pressão em calor; ou

(b) pelo atrito entre o fluido e a parede do meio poroso e, quanto maior a área de contato, maior será a resistência ao escoamento do fluido. 


\section{Resultados e discussão}

\section{Avaliação dos substratos}

\section{Rugosidade superficial dos blocos}

Apesar de haver base científica que demonstra a natureza química da aderência, a contribuição de um travamento mecânico não deve ser descartada, pois a aderência apresenta relação com os pontos de ancoramento na superfície (ANTUNES, 2006). Isso não significa que quanto maior a rugosidade, maior a aderência, pois fatores relacionados com o substrato ou com o material aplicado também devem ser considerados (COSTA, 2014).

A avaliação quantitativa de rugosidade superficial dos blocos é bastante simples, porém não é trivial diferenciar o que se trata de rugosidade e o que é porosidade, pois depende da determinação de um plano perpendicular à superfície e de um fator de escala (COSTA, 2014). Por exemplo, em uma superfície irregular há presença de picos e vales, significando o primeiro as imperfeições sobressalentes ao plano da superfície, e os vales considerados os poros.

Os blocos utilizados neste trabalho foram avaliados por interferometria e as imagens obtidas apresentadas na Figura 6, juntamente com os índices de superfície de cada substrato.

Como esperado, a superfície do bloco cerâmico é menos rugosa, com índice 1,39, e do bloco de concreto a mais rugosa, com índice de superfície 1,95. Em ensaio complementar realizado por porosimetria de intrusão de mercúrio (em um equipamento Micromeritics, AutoPore III, modelo 9410) indicou-se também a presença de poros menores no bloco de cerâmico, com diâmetro médio em torno de $2 \mu \mathrm{m}$.

Além da dependência da estrutura física da superfície do substrato, a capacidade de molhamento do revestimento aplicado ao bloco deve permitir a saturação das irregularidades da superfície de contato, com a fase líquida, ou seja, nos poros e rugosidades a fim de aumentar o potencial de ancoramento após a secagem.

A penetração das partículas finas e a precipitação dos cristais hidratados do cimento no interior dos poros superficiais depende da geometria e do tamanho das partículas da argamassa aplicada, ou seja: no caso de as irregularidades superficiais serem menores do que as partículas, não haverá penetração em função do entupimento da "entrada" do canal poroso.

\section{Figura 6 - Ilustração da rugosidade de cada substrato, salientando os índices de superfície}
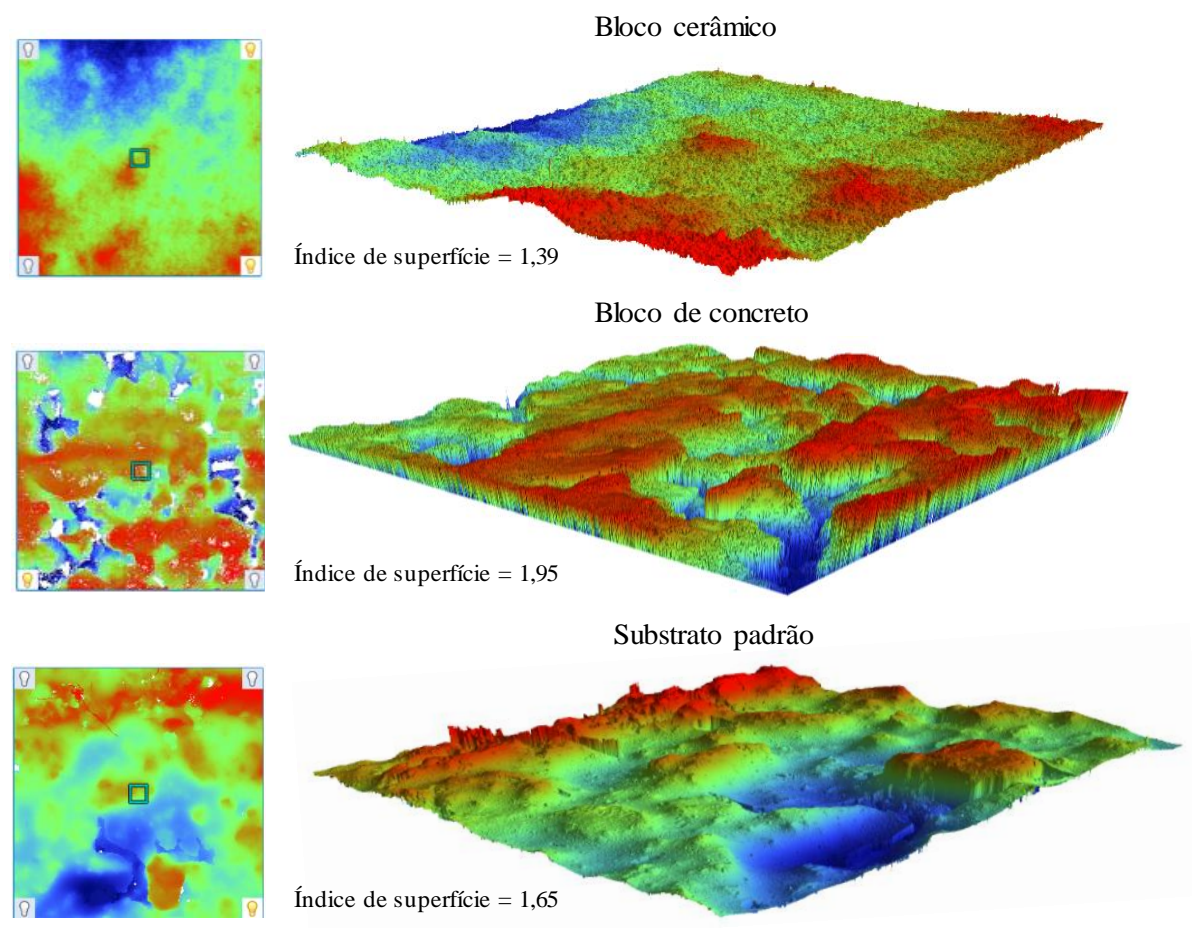

500 Bernardo, H. M.; Romano, R. C. de O.; Cincotto, M. A.; Pileggi, R. G. 
Sendo assim, haverá somente a penetração da solução iônica para o interior do substrato, e a formação dos cristais hidratados ocorrerá somente se houver concentração elevada de íons e espaço para a precipitação. Dessa forma, a capacidade de absorção de água dos blocos também é de grande relevância prática.

\section{Ângulo de contato da gota e absorção de água por capilaridade}

A tensão superficial do líquido sobre o substrato foi determinada a partir do ângulo de contato da gota, resultado apresentado na Figura 7. O valor do ângulo de contato depende principalmente da relação que existe entre as forças adesivas líquido/sólido e as forças coesivas do líquido. Quando as forças adesivas pela superfície do sólido são muito grandes em relação às forças coesivas, o ângulo de contato é menor que $90^{\circ}$, tendo como resultado o molhamento da superfície pelo líquido em questão.

É nítido que as gotas aplicadas sobre os blocos de referência, ou seja, sem tratamento superficial, foram absorvidas rapidamente, com exceção do substrato-padrão de concreto, no qual foi possível a determinação do ângulo de contato de forma adequada, conforme apresentado na Tabela 3.

Com o tratamento de superfície, seja a partir do uso de hidrofugante ou silicone, a gota foi mantida intacta por maior tempo, ou seja, parte da contribuição da absorção de água pelos blocos ou substrato-padrão de concreto foi eliminada das avaliações, sendo possível constatar que a camada protetora imposta pela aplicação do silicone dificultou mais a perda de água por sucção do que a obtida com o hidrofugante.

De acordo com o modelo de Wenzel, o líquido entra em contato com toda a superfície rugosa, preenchendo completamente as cavidades existentes. Cassie-Baxter, por outro lado, considera que o líquido não molha completamente a superfície rugosa, devido à existência de ar entre as depressões. Nesse caso, a interface da superfície do líquido é, na verdade, composta por duas fases (líquido-sólido e liquido-vapor) e cada uma contribui com um ângulo de contato diferente, sendo o ângulo de contato aparente a soma de todas as contribuições (VERPLANCK et al., 2007; SUBHASH LATTHE, 2012). No entanto, em nenhum dos casos descritos a absorção de água pelos blocos é considerada, sendo que os modelos propostos pelos autores admitem somente irregularidades superficiais.

Figura 7 - Ilustração da gota sobre os diferentes substratos após 2 min de contato

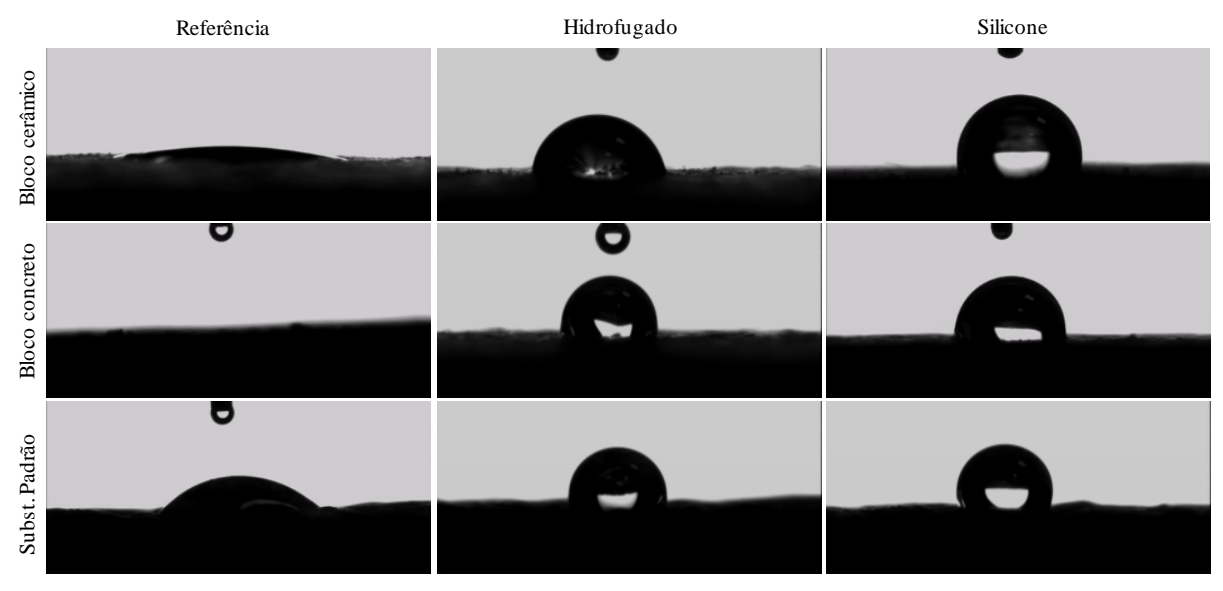

Tabela 3 - Ângulo de contato da gota em função do tipo de substrato e tratamento superficial

\begin{tabular}{c|c|c|c}
\hline $\begin{array}{c}\text { Tipo de } \\
\text { substrato }\end{array}$ & $\begin{array}{c}\text { Tratamento } \\
\text { superficial }\end{array}$ & $\begin{array}{c}\text { Ângulo da } \\
\text { gota }\left({ }^{\circ}\right)\end{array}$ & Desvio \\
\hline \multirow{2}{*}{ Bloco } & Referência & 15,0 & 0,8 \\
cerâmico & Hidrofugado & 89,6 & 3,2 \\
& Silicone & 96,9 & 4,6 \\
\hline \multirow{2}{*}{ Bloco de } & Referência & 3,0 & 0,2 \\
concreto & Hidrofugado & 78,3 & 3,9 \\
& Silicone & 85,6 & 6,7 \\
\hline Substrato- & Referência & 57,9 & 3,1 \\
padrão de & Hidrofugado & 96,5 & 1,0 \\
concreto & Silicone & 108,4 & 6,0 \\
\hline
\end{tabular}


A capacidade de absorção de água dos substratos avaliados neste trabalho, com e sem tratamento de superfície, foi monitorada em função da variação do coeficiente de capilaridade (W) e o resultado é apresentado na Figura 8. Adicionalmente, foi indicada a relação entre W e o tempo necessário para a saturação.

Comparando-se a absorção em cada bloco com os diferentes tratamentos superficiais, mantendo-se constante a rugosidade, foi observado que a utilização do silicone resultou em superfícies menos susceptíveis à penetração da água, e ocorreu nesses casos a saturação após 48 h de avaliação.

Como esperado, nos blocos sem tratamento a água foi absorvida rapidamente, atingindo a saturação nos blocos de concreto somente após 15 min de avaliação. A tendência observada foi de maior absorção no bloco de concreto e menor no substrato-padrão de concreto, com relação direta entre o coeficiente de absorção de água e o tempo de saturação.

Como o ângulo de contato pode ser modificado em função das características superficiais do substrato, como a rugosidade, presença de poros capilares, composição química, etc., a sucção capilar é uma característica tão importante quanto a rugosidade na avaliação da aderência, pois pode gerar canais permeáveis no interior do revestimento de argamassa e facilitar a percolação de ar ou líquido após o endurecimento da argamassa, afetando de forma indesejada a penetração dos agentes de degradação ao interior do componente.

Na prática não há uma superfície perfeitamente lisa para a aplicação da argamassa de revestimento ou com similar absorção de água, e as argamassas podem ser aplicadas em substratos com distintas características físicas, químicas e mineralógicas como blocos cerâmicos ou de concreto, estruturas de concreto, blocos alveolares, entre outros.

Conforme ilustrado na Figura 9, foi observada relação direta entre a absorção de água pelos diferentes blocos e o ângulo da gota aplicada em cada tipo de superfície de substrato, pois a gota aplicada sobre a superfície rugosa se espalha até encontrar um ponto de equilíbrio, atingindo um ângulo de contato aparente. Com esse espalhamento a interface líquido/ar da gota é substituída por uma superfície sólido/líquido com mesma área.

\section{Figura 8 - Absorção de água dos diferentes blocos: sem tratamento e recobertos com hidrofugante e silicone - abaixo, à direita, é ilustrada a relação entre o tempo de saturação e o coeficiente de absorção de água - W}
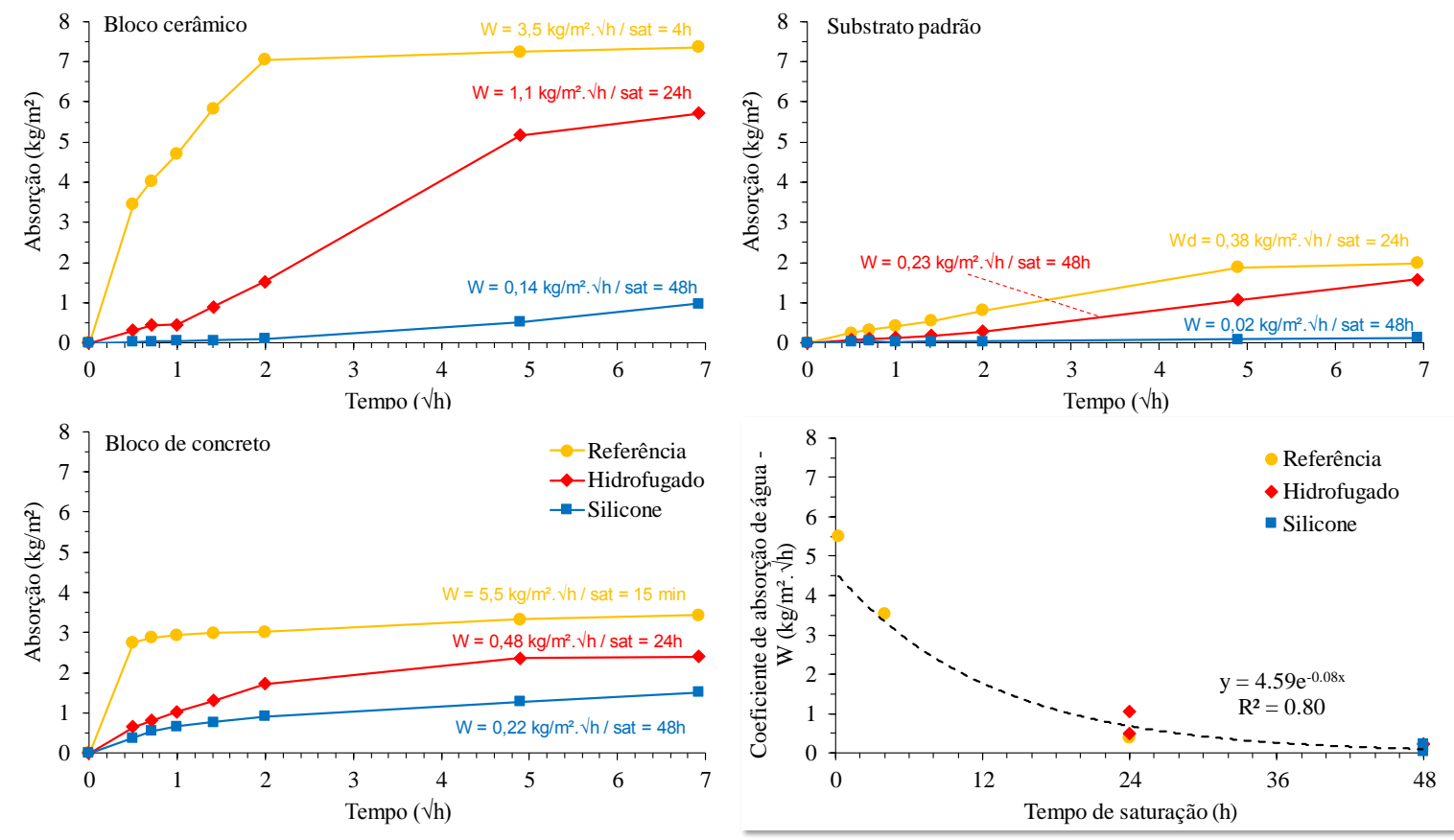

502 Bernardo, H. M.; Romano, R. C. de O.; Cincotto, M. A.; Pileggi, R. G. 
Figura 9 - Relação entre o ângulo da gota aplicada sobre os diferentes substratos e o coeficiente de absorção de água por capilaridade - W

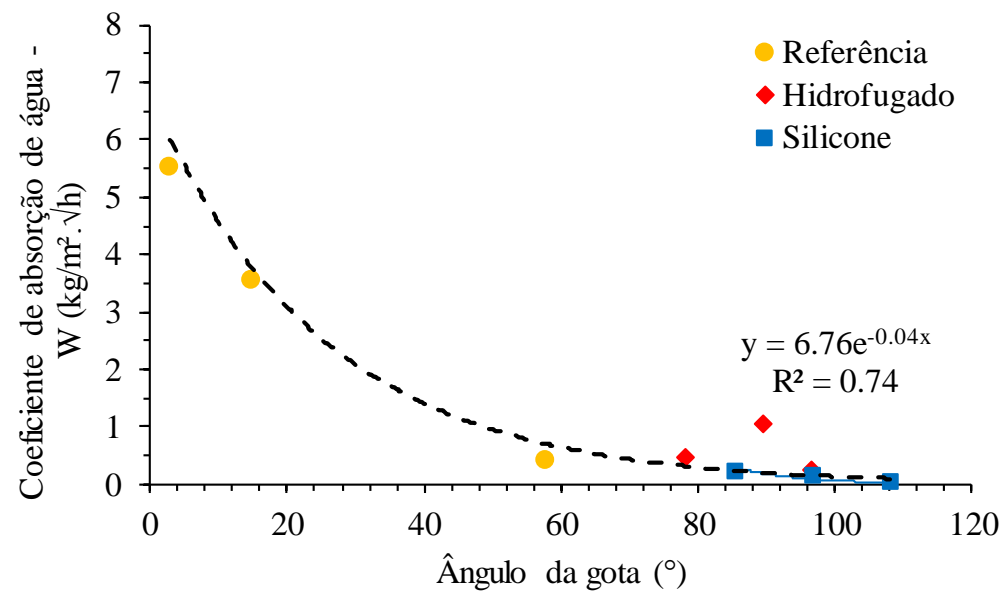

Usando a equação de ajuste indicada no gráfico poderia ser possível a predição da resistência de aderência de revestimentos de argamassa se a propriedade dependesse somente da absorção e da rugosidade. No entanto, a aderência depende de parâmetros mais complexos, principalmente como a ancoragem mecânica, propiciada pela penetração de partículas nos poros. Por isso, o uso de partículas finas associadas à dispersão adequada e tratamentos superficiais do substrato aumentam a aderência pelo acréscimo de contato matrizsubstrato. Tal aumento nos pontos de contato são influenciados também pela energia de aplicação e pelo adequado espalhamento das argamassas sobre os substratos (ANTUNES, 2006).

\section{Espalhamento das argamassas nos diferentes substratos}

Após a aplicação das argamassas sobre o substrato, há uma série de etapas subsequentes que interferem fortemente no desenvolvimento da resistência de aderência da argamassa à superfície. Tal mecanismo de interação pode ser dividido em (ANTUNES, 2006; BARBOSA, 2010):

(a) molhagem do substrato pelo contato com a argamassa e consequente sucção capilar;

(b) transporte das partículas mais finas para a interface devido ao fluxo capilar;

(c) equilíbrio da umidade entre substrato e argamassa;

(d) hidratação do cimento; e

(e) formação de fase sólida coesiva entre substrato e argamassa.

Sendo assim, entre a etapa de molhagem e o equilíbrio da umidade ocorre o mecanismo de absorção com perda de água para o substrato, estágio que está relacionado com o tamanho dos poros do substrato responsáveis pelo fluxo capilar e pela perda por evaporação.

De modo geral há um consenso de que a absorção do substrato possui função relevante no processo de desenvolvimento da resistência de aderência, visto que a adesão inicial ocorre em função da percolação da parcela líquida através dos poros (fenômeno de transporte).

No entanto, a influência da rugosidade superficial na aderência da argamassa é um dos pontos que provoca controvérsias (CARASEK, 1996; ANTUNES, 2006). Isso ocorre principalmente porque a maioria dos trabalhos não avalia as propriedades reológicas durante o espalhamento do revestimento sobre o substrato, etapa primordial para o desempenho adequado da argamassa no estado endurecido.

Para tentar entender tal lacuna, neste trabalho o espalhamento das argamassas sobre substratos com distintas rugosidades e taxas de absorção de água foi avaliado a partir do método squeeze flow; as imagens das argamassas antes (à esquerda) e após o teste (à direita) são apresentadas na Figura 10 (ilustração do espalhamento sobre o bloco cerâmico - hidrofugado e referência) e osresultados na Figura 11. Todos os testes foram realizados com 5 min e 30 min depois da moldagem. 
Figura 10 - Ilustração do ensaio de squeeze flow sobre o bloco cerâmico - a direita é apresentada a diferença de espalhamento em função do tratamento do substrato com hidrofugante, fato ocorrido também nas demais substratos
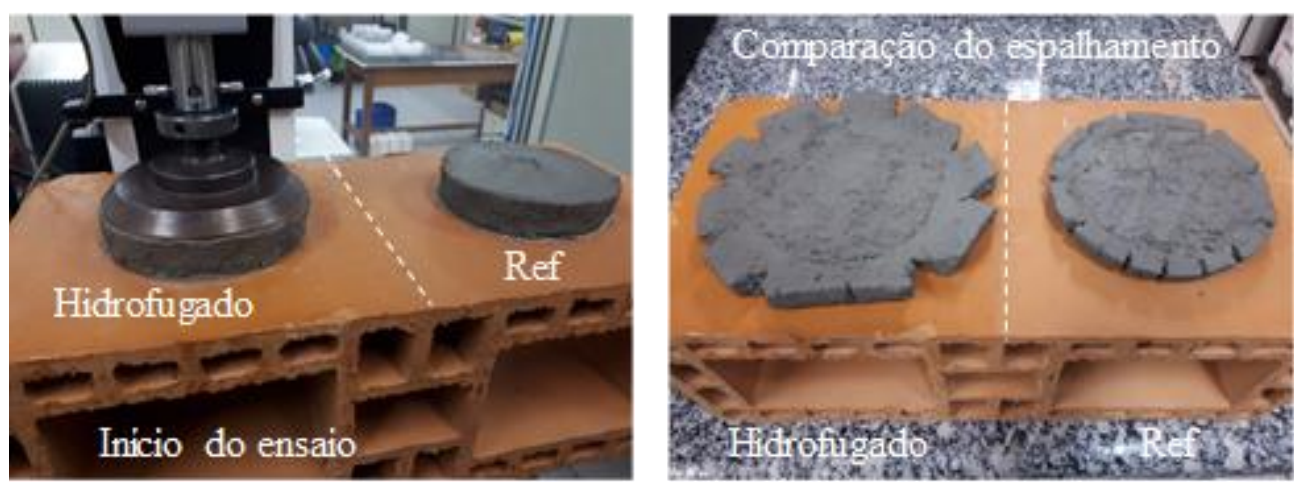

Figura 11 - Espalhamento das argamassas sobre os diferentes substratos e após os distintos tratamentos superficiais
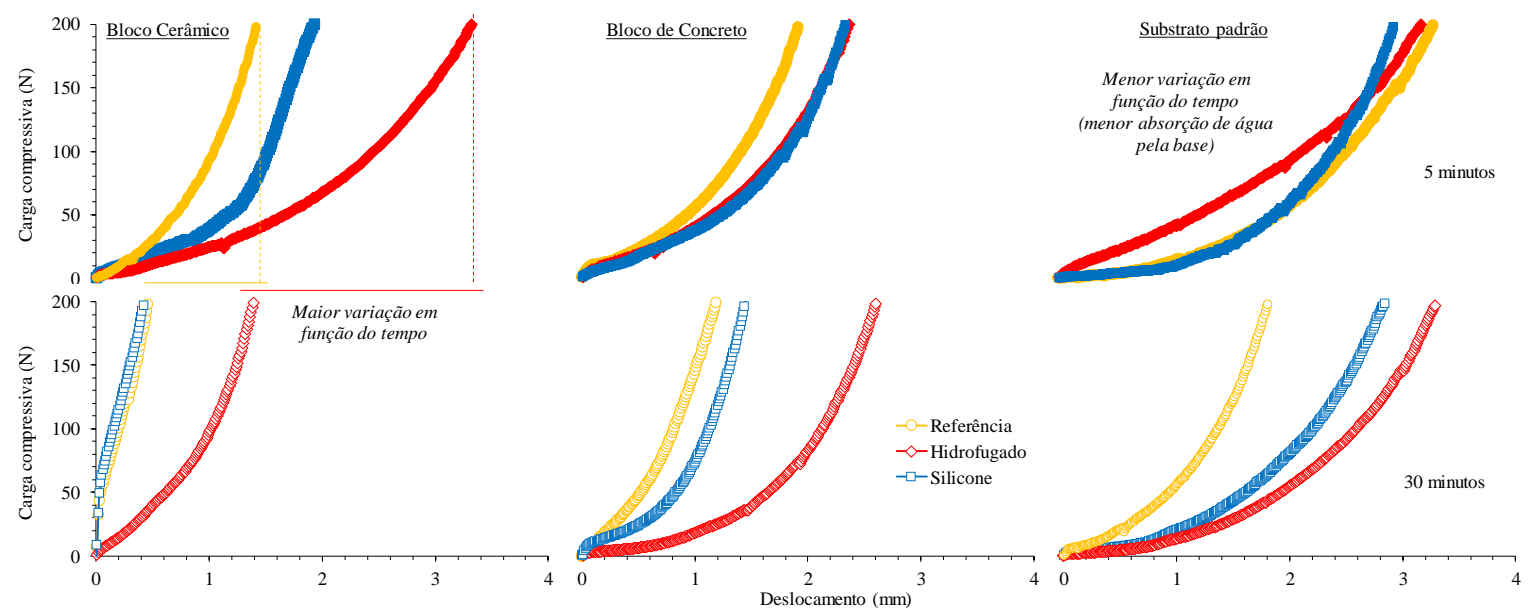

Tanto a rugosidade do substrato quanto a viscosidade da argamassa podem interferir na molhagem e, por conseguinte, na absorção de água pelo substrato, pois se a argamassa ou a pasta não está totalmente em contato com a superfície do substrato, pode ocorrer menor sucção de água devido aos vazios entre o revestimento e o substrato.

Independentemente disso, o espalhamento da argamassa sobre o substrato é uma função linear e inversamente proporcional ao teor de água absorvido pelo substrato.

Barbosa (2010) avaliou o comportamento de pasta cimentícia aplicada em substratos com porosidade de $28 \%$ e $40 \%$ após 5 min e 10 min do contato matriz-substrato e verificou que ambos os substratos apresentaram o mesmo comportamento após $5 \mathrm{~min}$ de contato, mas, após $10 \mathrm{~min}$ de absorção de água foi necessária uma carga mais elevada para a obtenção de mesmo espalhamento no substrato com maior porosidade. De acordo com Barbosa (2010), a avaliação na pasta foi realizada principalmente porque se trata da parcela mais susceptível aos efeitos de sucção capilar.

No entanto, a argamassa de revestimento é uma composição heterogênea, formulada com ampla extensão granulométrica e utilizando-se matérias-primas com distintas características físico-químicas e mineralógicas, que deve fluir de forma homogênea quando aplicada sobre a substrato. Por isso, a água utilizada para a mistura tem a função de recobrir a superfície das partículas e afastá-las para tornar o conjunto fluido.

Quanto mais rápida a perda de água, seja para a substrato ou para o ambiente, mais rápida é a aproximação das partículas, com menor quantidade de fluido para reduzir as forças de atrito que atuam entre elas, o que dificulta o espalhamento do revestimento sobre o substrato: a diminuição da mobilidade durante o espalhamento provoca o enrijecimento da argamassa.

504 Bernardo, H. M.; Romano, R. C. de O.; Cincotto, M. A.; Pileggi, R. G. 
Tal restrição da mobilidade da argamassa pode aumentar a quantidade de defeitos na interface com o substrato e, consequentemente, diminuir a resistência de aderência.

Ficou claro para o bloco cerâmico, em função da maior taxa de absorção de água, que 5 min após a aplicação do revestimento há diferenças consideráveis em função do tratamento da superfície.

Por outro lado, no substrato-padrão de concreto, principalmente quando realizado o tratamento da superfície, foi mais estável quanto ao espalhamento após $30 \mathrm{~min}$ de espera, ou seja, a absorção mais lenta de água pelo substrato resultou em espalhamentos similares após $5 \mathrm{~min}$ ou $30 \mathrm{~min}$.

Em suma, conforme apresentado na Figura 12, a relação entre o espalhamento (deslocamento) obtido no ensaio squeeze flow, a absorção de água por capilaridade (W) e o ângulo de contato da gota ilustra de forma mais coerente o que ocorre nas argamassas durante o desenvolvimento da resistência de aderência, ou seja: um adequado recobrimento da superfície do substrato possibilita a redução dos defeitos interfaciais e aumento dos pontos de contato entre a argamassa e a substrato, e a absorção dos íons pela sucção capilar auxilia na precipitação dos compostos hidratados do cimento.

\section{Resistência de aderência e permeabilidade das argamassas aplicadas}

Após 28 dias de cura, foram avaliadas a resistência de aderência e a permeabilidade ao ar da argamassa aplicada sobre os diferentes substratos e com distintos tratamentos de superfície, resultados apresentados na Figura 13.

Fica nítida a tendência de diminuição dos valores médios obtidos em ambos os casos, com o tratamento da superfície, sendo a aplicação do silicone mais crítica para o desenvolvimento da resistência na interface substrato-argamassa, porém com considerável ganho na estanqueidade do sistema.

A permeabilidade ao ar das argamassas não apresenta valores normalizados, mas espera-se sempre que os revestimentos apresentem menor susceptibilidade à penetração dos agentes de degradação. Por isso, os resultados obtidos servem somente de base comparativa para avaliação da argamassa utilizada neste trabalho em função do tipo de substrato e tratamento superficial. No entanto, baseado em levantamentos apresentados por Cardoso (2009) ou Maciel et al. (2018), a argamassa aplicada apresenta-se em conformidade com resultados obtidos para produtos comercializados no mercado brasileiro e em alguns países europeus.

Figura 12 - Relação entre o espalhamento obtido no ensaio squeezeflow, a absorção de água por capilaridade (W) e o ângulo de contato da gota - os dois últimos são parâmetros de caracterização do substrato

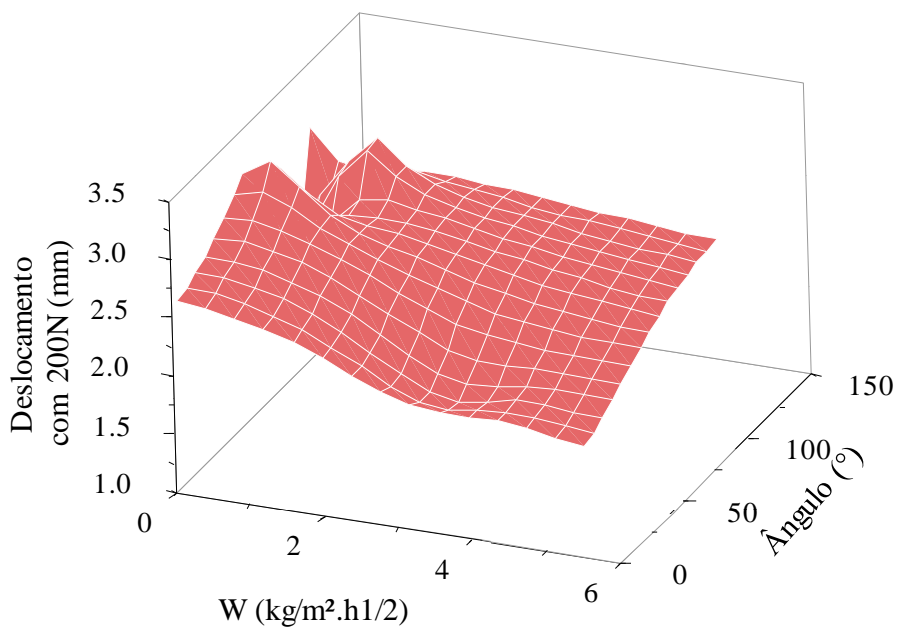


Figura 13 - Resistência de aderência à tração (acima) e permeabilidade ao ar (abaixo) em função do tipo de substrato e tratamento da superfície

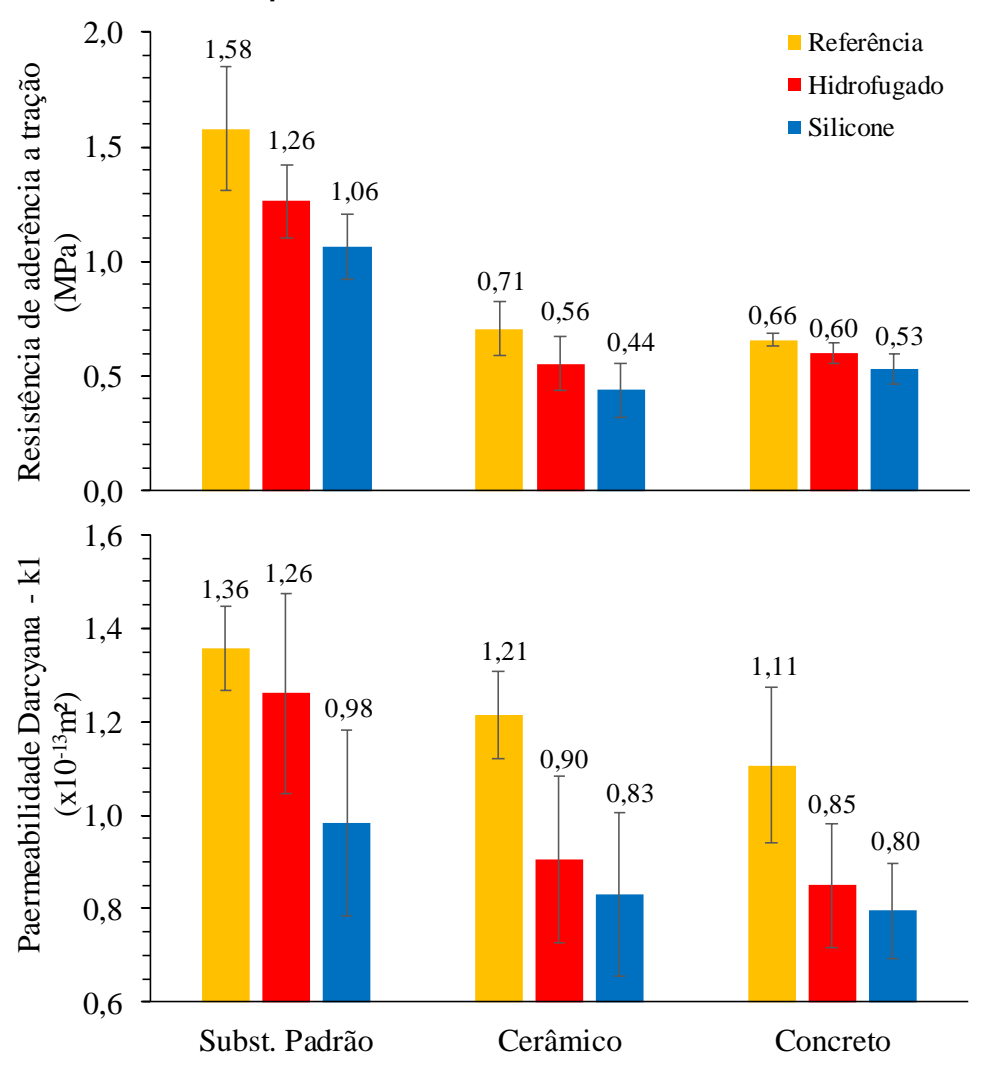

Da mesma forma, os resultados da resistência de aderência à tração, apesar de terem sido menores nos substratos com aplicação de silicone líquido, estão em conformidade com a norma NBR 13528 (ABNT, 2012a) para argamassas aplicadas sobre substrato-padrão de concreto. A avaliação da resistência da argamassa sobre o substrato-padrão pode resultar em informações relevantes e próximas do ambiente de obra quando a argamassa é aplicada sobre pilares de concreto. No entanto, há uma discrepância muito grande entre os valores atingidos para a argamassa aplicada sobre os blocos de concreto e cerâmicos. Essa é uma observação que põe em dúvida a adoção do limite mínimo de resistência de aderência da referida norma e, apesar da conformidade normativa, pode não garantir o adequado desempenho nas obras.

As duas propriedades foram avaliadas também em função da absorção do substrato e os resultados são os apresentados na Figura 14. À esquerda são ilustrados os dados compilados em função do tipo de bloco e, à direita, em função do tratamento superficial para facilitar a comparação. Trata-se de dois parâmetros utilizados para a avaliação da durabilidade dos revestimentos de argamassa, que devem permanecer aderidas por toda a vida útil ao mesmo tempo em que deve ser estanque à penetração dos agentes de degradação.

A primeira informação relevante é que há excelente correlação entre o coeficiente de capilaridade do bloco e a resistência ao arrancamento ou permeabilidade ao ar. Essa tendência foi independente do tipo de tratamento da superfície, porém com menor coeficiente de correlação $\left(\mathrm{R}^{2}\right)$ para o silicone $(0,73)$.

Avaliando-se a resistência ao arrancamento somente em função do tipo de bloco, ou seja, mantendo-se a mesma rugosidade superficial e alterando-se a absorção de água pelo substrato (W), fica muito nítido que a argamassa aplicada sobre substrato-padrão apresentou valores no mínimo duas vezes maiores do que os obtidos para os blocos cerâmico ou de concreto. Além disso, quanto maior o valor de W maior a resistência de aderência média e os resultados obtidos para a argamassa aplicada sobre os blocos cerâmico e de concreto foram similares entre si e distintos do obtido para o substrato-padrão de concreto. 
Figura 14 - Relação entre a resistência de aderência à tração (acima) ou permeabilidade ao ar das argamassas (abaixo) e o coeficiente de absorção dos blocos: (a) e (c) ilustram o resultado em função do tipo de bloco e (b) e (d) em função do tratamento da superfície

Tipo de bloco

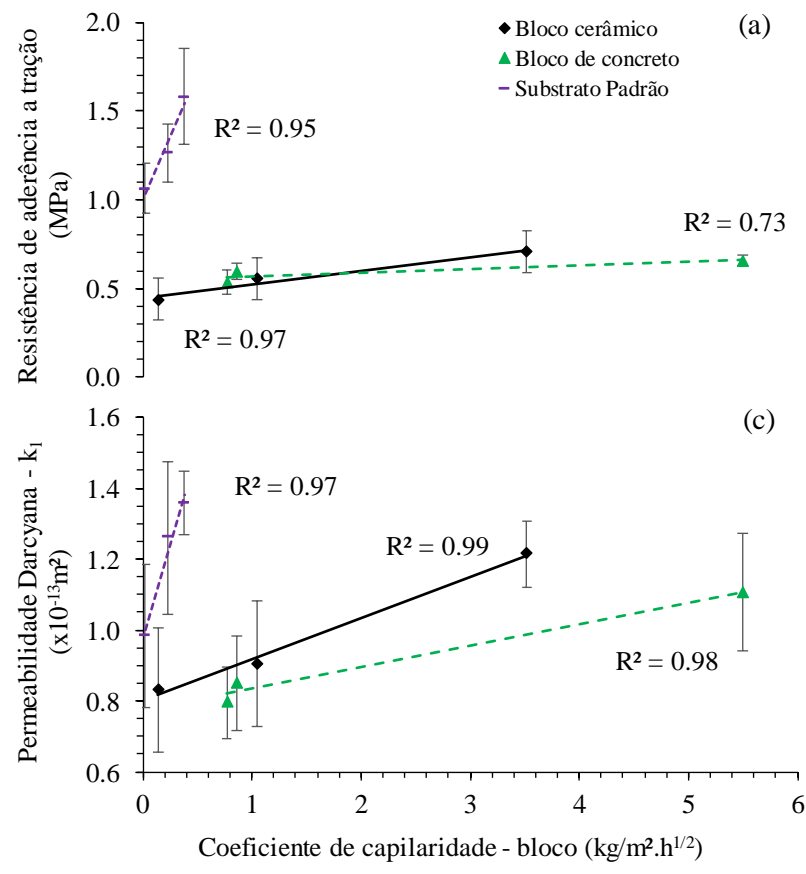

(a)

Tratamento da superfície

(b)

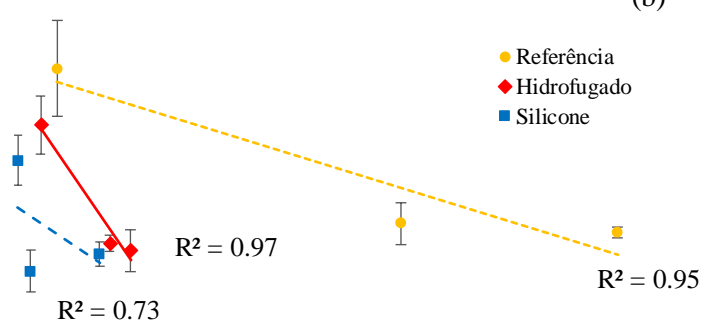

(d)

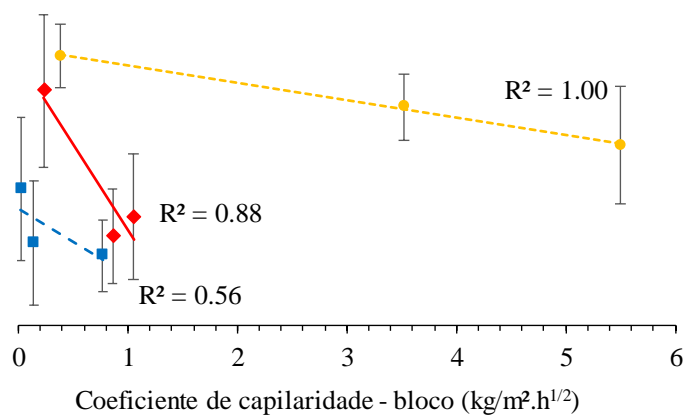

Com relação à permeabilidade ao ar, apesar de ser obtida uma relação linear e diretamente proporcional com W, não foram observadas diferenças estatisticamente significativas (a partir de Anova - fator único) entre os a argamassa aplicada sobre os blocos de concreto e cerâmico ou substrato-padrão de concreto com tratamento com silicone ou hidrofugante. Somente a argamassa aplicada sobre o bloco cerâmico sem tratamento resultou em maior permeabilidade do que as demais e esse fato foi atribuído à perda de água considerável para o substrato, criando canais percoláveis em função do arraste de partículas que podem diminuir a estanqueidade do conjunto.

Por outro lado, avaliando-se os resultados em função do tratamento da superfície, ou seja, correlacionandose a resistência de aderência e a permeabilidade dos blocos com distintas rugosidades, foi possível observar relação inversamente proporcional com a absorção de água para o substrato em ambas as propriedades.

Porém, as diferenças estatísticas foram detectadas somente comparando-se os blocos de referência (sem tratamento) e siliconados. Nos blocos hidrofugados houve similaridade estatística em ambos os casos.

É possível considerar, então, que o tipo de hidrofugante utilizado auxiliou tanto na redução de absorção de água para o substrato quanto na intensificação das pontes de aderência, fenômeno não ocorrido com o tratamento superficial com silicone.

O silano, composto ativo do hidrofugante utilizado, é uma molécula composta de um átomo de silício central com quatro ligações que podem ser substituíveis por praticamente qualquer combinação de grupos não reativos, reativos inorganicamente ou reativos organicamente. Como são produtos com pequena estrutura molecular (diâmetro de $1,0 \times 10^{-6}$ a $1,5 \times 10^{-6} \mathrm{~mm}$ ), penetram eficientemente mesmo em substratos bem densos (MEDEIROS; GOMES; HELENE, 2006) e reagem entre si e com quaisquer grupos hidroxílicos $\left(\mathrm{OH}^{-}\right)$ dentro do substrato, geralmente quando há presença de umidade, formando uma rede de resina de silicone.

A camada de silano aplicada na superfície dos blocos deveria impedir a penetração de água nos poros pela modificação da energia superficial, mas permitir o transporte de fluidos gasosos. Sendo assim, a penetração dos íons solúveis do cimento durante a hidratação deveria ser dificultada, diminuindo a formação dos compostos hidratados nos poros dos blocos. No entanto, o aumento da resistência de aderência ocorreu em função da formação de ligações cruzadas entre o silano da superfície do bloco e a camada intermediária de água do C-S-H nano estruturado formado durante a hidratação do cimento na superfície. 
Por fim, correlacionando-se ambos os parâmetros de durabilidade avaliados, conforme apresentado na Figura 15, foi possível concluir, mesmo com os consideráveis desvios dos métodos, que para a forma de execução do revestimento utilizada neste trabalho, quanto maior a resistência de aderência, maior a permeabilidade da argamassa, principalmente em função da criação de vazios percoláveis, formados pelo arraste do líquido durante a sucção capilar pelo substrato.

O comportamento foi similar entre os blocos cerâmico e de concreto, porém distinto do observado para o substrato-padrão de concreto, no qual a resistência de aderência foi no mínimo duas vezes maior. Por isso, é razoável afirmar que apesar da absorção influenciar nos parâmetros de durabilidade, não se pode utilizar os resultados obtidos de resistência ao arrancamento de argamassas aplicadas sobre substrato-padrão como parâmetro de desempenho para argamassas aplicadas sobre diferentes substratos.

\section{Considerações finais}

Este trabalho foi realizado com o objetivo de analisar o impacto da absorção dos substratos na avaliação da resistência de aderência e permeabilidade de argamassa aplicada sobre diferentes blocos e com distintos tratamentos superficiais (silicone ou hidrofugante à base de silano).

Na caracterização dos blocos observou-se a relação direta esperada entre a absorção de água e o ângulo da gota séssil sobre a superfície tratada.

O espalhamento da argamassa sobre os substratos, determinado a partir do ensaio squeeze flow, apresentou relação com a absorção de água, sendo mais fácil a aplicação nos blocos hidrofugados. Isso resultou em maior teor de água concentrado na própria argamassa por ter perdido menos líquido para o substrato por absorção.

Houve correlação entre o coeficiente de capilaridade do bloco e a resistência ao arrancamento ou à permeabilidade ao ar e essa tendência ocorreu independentemente do tipo de tratamento da superfície, porém com menor coeficiente de correlação $\left(\mathrm{R}^{2}\right)$ para o silicone.

Mantendo-se a rugosidade superficial e alterando-se a absorção de água pelo substrato (W), ficou muito nítido que a argamassa aplicada sobre substrato-padrão de concreto apresentou valores no mínimo duas vezes maiores do que os obtidos para os blocos cerâmico ou de concreto.

O efeito dos tratamentos de superfície na absorção de água (W) do substrato de revestimento, sem interferência da rugosidade, foi determinado com o substrato-padrão de concreto, que se considera com rugosidade uniforme e constante para os corpos-de-prova moldados. Comparativamente, ambos os blocos apresentaram absorção duas vezes maior do que o substrato-padrão tratado com o hidrofugante ou com o silicone.

Quanto maior a absorção de água pelo substrato, maior a resistência de aderência média, sendo os resultados obtidos nas argamassas aplicadas sobre os blocos cerâmico e de concreto estatisticamente similares entre si e distintos do obtido para a argamassa aplicada sobre o substrato-padrão de concreto.

Figura 15 - Relação entre a resistência de aderência à tração e permeabilidade ao ar das argamassas: à esquerda é apresentado o resultado em função do tipo de bloco e à direita em função do tratamento da superfície

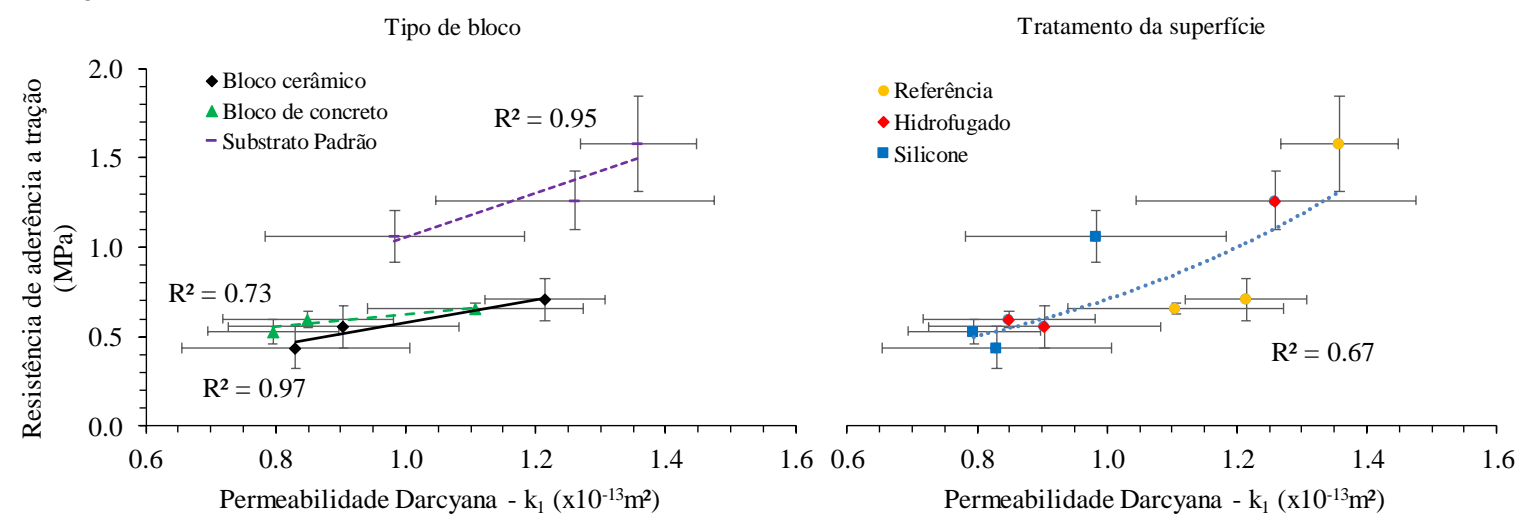

508 Bernardo, H. M.; Romano, R. C. de O.; Cincotto, M. A.; Pileggi, R. G. 
Por outro lado, no caso da permeabilidade ao ar não foram observadas diferenças estatisticamente significativas entre as argamassas aplicadas sobre os blocos de concreto e cerâmico ou substrato- padrão de concreto com tratamento com silicone ou hidrofugante. Somente a argamassa aplicada sobre o bloco cerâmico sem tratamento resultou em maior permeabilidade do que as demais, fato atribuído à considerável perda de água para o substrato, criando canais percoláveis em função do arraste de partículas que podem diminuir a estanqueidade do conjunto.

Por fim, as propriedades avaliadas nesta argamassa seguiram as mesmas tendências, ou seja, quanto maior a resistência de aderência maior a permeabilidade da argamassa, mesmo não sendo propriedades correlacionadas. Além disso, os valores obtidos foram similares entre os blocos cerâmico e de concreto, porém distinto do observado para o substrato-padrão de concreto.

Por isso, apesar de a absorção influenciar nos parâmetros de durabilidade, não se pode utilizar somente os resultados obtidos de resistência ao arrancamento sobre substrato-padrão de concreto para a avaliação das argamassas aplicadas sobre diferentes substratos, pois os valores obtidos foram muito maiores que os obtidos para os demais blocos.

Além disso, pode-se obter uma argamassa com adequada resistência ao arrancamento, porém com maior susceptibilidade à penetração dos agentes de degradação, ambos fatores que controlam a durabilidade das argamassas aplicadas.

\section{Referências}

ANGELIM, R. R.; ANGELIM, S. C. M.; CARASEK, H. Influência da distribuição granulométrica da areia no comportamento dos revestimentos de argamassa. In: SIMPÓSIO BRASILEIRO DE TECNOLOGIA DAS ARGAMASSAS, 3., São Paulo, 2003. Anais [...] São Paulo, 2003.

ANTUNES, R. P. N. Influência da reologia e da energia de impacto na resistência de aderência de revestimentos de argamassa. São Paulo, 2006.Tese (Doutorado em Engenharia Civil) - Escola de Engenharia, Universidade de São Paulo, São Paulo, 2006.

ASSOCIAÇÃO BRASILEIRA DE NORMAS TÉCNICAS. NBR 13528: revestimento de paredes e tetos de argamassas inorgânicas: determinação da resistência de aderência à tração. Rio de Janeiro, 2010a.

ASSOCIAÇÃO BRASILEIRA DE NORMAS TÉCNICAS. NBR 14082: argamassa colante industrializada para assentamento de placas cerâmicas: execução do substrato padrão e aplicação de argamassa para ensaios. Rio de Janeiro, 2004.

ASSOCIAÇÃO BRASILEIRA DE NORMAS TÉCNICAS. NBR 15839: argamassa de assentamento e revestimento de paredes e tetos: caracterização reológica pelo método squeezeflow. Rio de Janeiro, $2010 \mathrm{~b}$.

BARBOSA, W. S. Alteração do comportamento reológico da suspensão cimentícia aplicada sobre substratos porosos. São Paulo, 2010. 152 f. Dissertação (Mestrado em Engenharia Civil - Escola Politécnica, Universidade de São Paulo,2010.

BRITISH STANDARD. ES EN ISO 15148: hygrothermal performance of buildings materials and products: determination of water absorption coefficient by partial immersion. London, 2002

CARASEK, H. Aderência de argamassas à base de cimento Portland a substratos porosos: avaliação dos fatores intervenientes e contribuição ao estudo do mecanismo da ligação. 285 f. São Paulo, 1996. Tese (Doutorado em Engenharia Civil) - Escola Politécnica, Universidade de São Paulo, 1996.

CARASEK, H.; SCARTEZINI, L. M. B. Evolução da resistência de aderência dos revestimentos de argamassa mista. In: SIMPÓSIO BRASILEIRO DE TECNOLOGIA DAS ARGAMASSAS, 3., Vitória, 1999. Anais [...] Vitória: ANTAC, 1999.

CARBONE, C. E., SANTOS, H., ROMANO, R. C. O., PILEGGI, R. G. Efeito da adição de látex nas pastas de cimento branco no estado endurecido. Ambiente Construído v. 13, n. 3, p. 317-330, 2013. ISSN 16788621.

CARDOSO F. A. Método de formulação de argamassas de revestimento baseado em distribuição granulométrica e comportamento reológico. São Paulo, 2009. Tese (Doutorado em Engenharia Civil) Escola Politécnica, Universidade de São Paulo, São Paulo, 2009.

COSTA, E. B. C. Análise de parâmetros influentes na aderência de matrizes cimentícias. São Paulo, 2014. 156 f. Tese (Doutorado em Engenharia Civil) - Escola Politécnica, Universidade de São Paulo, 2014. 
INNOCENTINI, M. D. M. et al. Otimização da permeabilidade de filtros de aerossóis para altas temperaturas preparados a partir da técnica de adição de espuma aquosa em suspensão cerâmica. Cerâmica, v. 55, p. $67-77,2009$.

INNOCENTINI, M. D. M. et al. Permeability optimization and performance evaluation of hot aerosol filters made using foam incorporated alumina suspension. Journal of Hazardous Materials, v. 162, p. 212-221, 2009.

MACIEL, M. H. et al. Efeito da variação do consumo de cimento em argamassas de revestimento produzidas com base nos conceitos de mobilidade e empacotamento de partículas. Ambiente Construído, Porto Alegre, v. 18, n. 1, p. 245-259, jan./mar.2018.

MANTELLATO, S.; PALACIOS, M.; FLATT, R. J. Reliable specific surface area measurements on anhydrous cements.Cement and Concrete Research, v. 67, p. 286-291, 2015.

MEDEIROS, M.H. F.; GOMES, T. S.; HELENE, P. Hidrofugantes de superfície: estudo da capacidade de barrar o ingresso de água no concreto. Teoria e Prática na Engenharia Civil, v.8, p.21-28, 2006.

NAKAKURA, E. H.; CINCOTTO, M. A. Análise dos requisitos de classificação de argamassas de assentamento e revestimento. Boletim Técnico da Escola Politécnica da USP, Departamento de Engenharia de Construção Civil - BT/PCC/359. 2004.

NAKAKURA, E.; MUNHOZ, F. A. C.; BATTAGIN, A. Evolução da aderência em sistema de revestimento de argamassa. In: SIMPÓSIO BRASILEIRO DE TECNOLOGIA DAS ARGAMASSAS, 8., Curitiba, 2008. Anais [...] Curitiba, 2008.

OLIVEIRA, I. R. et al. Dispersão e empacotamento de partículas. São Paulo: Fazendo Arte, 2000.

PAES, I. N. et al.Influencia del transporte de agua enmorteros de revestimiento, enlaresistencia a laadherencia. Revista Ingeniería de Construcción,v. 29, n. 2, p. 175-186, 2014.

ROMANO, R. C. O. Incorporação de ar em materiais cimentícios aplicados em construção civil. São Paulo, 2013. Tese (Doutorado em Engenharia Civil) - Escola Politécnica, Universidade de São Paulo, 2013.

ROMANO, R. C. O.; TORRES, D. R.; PILEGGI, R. G. Impact of aggregate grading and air-entrainment on the properties of fresh and hardened mortars. ConstructionandBuildingMaterials, v. 82, p. 219-226, 2015.

SENTONE, D. S. Desenvolvimento de método para medida de permeabilidade superficial de revestimento de argamassa. São Paulo, 2011. Dissertação (Mestrado em Engenharia Civil) - Escola Politécnica, Universidade de São Paulo, 2011.

SUBHASH LATTHE, S. Recent progress in preparation of superhydrophobic surfaces: a review. Journal of Surface Engineered Materials and Advanced Technology, v. 2, p. 76-94, 2012.

TEMP, A. L. et al. Avaliação de revestimentos de argamassas à permeabilidade e a aderência à tração. In: SIMPÓSIO BRASILEIRO DE TECNOLOGIA DAS ARGAMASSAS, 10., Fortaleza, 2013. Anais [...] Fortaleza, 2013.

TORRENT, R. J. A two-chamber vacuum cell for measuring the coefficient of permeability to air of the concrete cover on site. Material Structure, v. 25, p. 358-365, 1992.

TORRENT, R. J.; FRENZER, G. Methods for measuring and assessing the characteristics of concrete cover on site. Zürich, 1995. Report \# 516, Office Fedéral des Routes.

VERPLANCK, N. et al. Wettability Switching Techniques on Superhydrophobic Surfaces. Nanoscale Research Letters, v. 2, p. 577-596, 2007.

\section{Agradecimentos}

Os autores agradecem ao Laboratório de Microestrutura e Ecoeficiência de Materiais, à Alcoa Foundation pelo apoio financeiro, à Capes/Brasil pela bolsa de Pós-Doutorado e à Fapesp (Projeto 2014/50948-3 - INCT CEMtec - Tecnologias CimentíciasEcoeficientes Avançadas) pelo apoio durante a realização do trabalho. 
Heitor Montefusco Bernardo

Departamentode Construção Civil, Escola Politécnica | Universidade de São Paulo | Av. Professor Almeida Prado, Trav. 2,83 | São Paulo SP - Brasil | | CEP 05508-010

Tel.: (11) 3091-5283 | E-mail: heitor.bernardo@lme.pcc.usp.br

Roberto Cesar de Oliveira Romano

Departamentode Construção Civil, Escola Politécnica | Universidade de São Paulo | Tel.: (11) 3091-5248 | E-mail: rcorjau@gmail.com

Maria Alba Cincotto

Departamentode Construção Civil, Escola Politécnica | Universidade de São Paulo | Tel.: (11) 3091-5792 | E-mail:

cincotto@lme.pcc.usp.br

Rafael Giuliano Pileggi

Departamentode Construção Civil, Escola Politécnica | Universidade de São Paulo | Tel.: (11) 3091-5442 | E-mail: rafael.pileggi@lme.pcc.usp.br

Ambiente Construído

Revista da Associação Nacional de Tecnologia do Ambiente Construído

Av. Osvaldo Aranha, $99-3^{\circ}$ andar, Centro

Porto Alegre - RS - Brasil

CEP $90035-190$

Telefone: +55 (51) 3308-4084

Fax: +55 (51) 3308-4054

www.seer.ufrgs.br/ambienteconstruido

E-mail: ambienteconstruido@ufrgs.br 